\title{
THE COMPARING OF THE SELECTED TEMPERATURE SENSORS COMPATIBLE WITH THE ARDUINO PLATFORM
}

\author{
Emil ŠKULTÉTY, Elena PIVARČIOVÁ*, Ladislav KARRACH \\ Technical University in Zvolen
}

\begin{abstract}
:
One of the most frequently measured quantity is temperature, which is also one of the most important physical quantities. Temperature has influence on the almost all states and processes in the nature as well as in technique. A wide range of temperature sensors is currently available on the market. They use different measurement principles and exist in many designs. According to the location of the sensing element in the measured environment, they are divided into two main groups: contact and non-contact. Further, we can divide the temperature sensors according to the physical principle on which they work. The article deals with the analysis and comparison of selected Arduino-compatible contact temperature sensors. The temperature measurement of machine functional nodes and its diagnostics are part of maintenance and engineering diagnostics. At present, NC and CNC machine diagnostics are an important trend in machine condition monitoring and machine status prediction to maintain production quality. Machine status monitoring allows reducing of machine service costs as well as maintaining the high production quality.
\end{abstract}

Key words: temperature, sensor, measurement, Arduino

\section{INTRODUCTION}

The temperature is one of the most important thermodynamic properties which determine the state of matter and is presented in many physical laws. There are very few properties of substances that are not temperature dependent [1].

For a quantitative description of different thermal states, it is necessary to assign the numerical values to them and so define a temperature scale. Two scales were standardized to measure the temperature: the Kelvin and the Celsius temperature scale [2].

The current level of progress is influenced by advanced information technologies [3]. In automation technique, the temperature belongs to the most monitored quantities in production and also non-production processes and the quality and production cost of many products and services often depend on its accuracy [4]. For example, the accurate measurement of the temperature in metallurgy is essential mainly due to the high quality requirements for casting products. Quality can be achieved only by strict compliance to the technological regulations, where knowledge of temperature and other physical and chemical properties of the melt play a major role [5].

High reliability of technical systems is a prerequisite for their efficient use and safety [6]. Reliability as one of the key features of the quality of each technical device is subject to effective monitoring of the technical state of the object and by early detection of physical changes and processes [7]. At the same time, temperature is the most common malfunctioning factor in measuring physical and chemical quantities, so it is often necessary to compensate its influence on the measurement of the requested quantity, which requires temperature measurement [4]. Sensors with different physical principles are used for temperature measurement. According to the principle they use, we can divide them into resistive, thermoelectric, semiconductor, monocrystalline, thermistors, dilatation, optical, chemical etc. Furthermore, they are divided into contact and non-contact sensors, according to whether or not they have contact with the measured environment. Despite the increasing importance of non-contact measuring methods, industrial temperature is measured by contact methods [8].

\section{METHODOLOGY OF RESEARCH}

There are available many types of sensors and devices on the market for temperature measurement. It is not easy to select the most appropriate equipment from such a wide variety. [9]. The sensors, which we have chosen for comparison, comply with following conditions: they can be connected to Arduino platform, for processing the information from the sensors it is not necessary to program complicated programs and they don't need several other components and ICs for correct functioning. For example, the resistance temperature sensor Pt100, which is used in 
various applications, needs Wheatstone bridge circuit for evaluation. Temperature can be measured using deflection or compensation method.

On the base of above mentioned conditions we have selected the sensors LM35DZ, DS18B20 and AM2320, which are often used in applications based on Arduino platform e.g. meteo stations, temperature control in the flat or the intelligent greenhouse.

The reference temperature was verified using a universal measuring instrument, ALMEMO 2590-4AS. The first sensor in comparison is LM35DZ. It is semiconductor temperature sensor with analog output. The temperature measurement with this sensor can be more accurate than the measurement with thermistors [10]. The LM35 device is rated to operate over a $-55^{\circ} \mathrm{C}$ to $150^{\circ} \mathrm{C}$ temperature range. The important advantage against the other sensors is that, the analog output is directly proportional to temperature in ${ }^{\circ} \mathrm{C}[11]$. The basic parameters are shown in Table 1.

Table 1 Parameters of the $L M 35 D Z$

\begin{tabular}{lr}
\hline Temperature-Voltage scale factor & $+10 \mathrm{mV} /{ }^{\circ} \mathrm{C}$ \\
Measurement range & $-55-150^{\circ} \mathrm{C}$ \\
Supply voltage & $4-30 \mathrm{~V}$ \\
Current drain & $60 \mu \mathrm{A}$ \\
Self-heating & $0.08^{\circ} \mathrm{C}$ \\
Accuracy & $\pm 3 / 4^{\circ} \mathrm{C}$ \\
Package & $\mathrm{TO}-92$ \\
\hline
\end{tabular}

The second sensor in comparing is DS18B20. This digital thermometer provides digital output and communicates over a 1-Wire bus that by definition requires only one data line (and ground) for communication with a central microprocessor. The DS18B20 has a unique 64-bit serial code, which allows multiple DS18B20s to function on the same 1-Wire bus [12]. The analog-to-digital converter (ADC), coupled to the temperature sensing unit, converts temperature to 9-12 bit word. The measurement range of sensor is from $-55^{\circ} \mathrm{C}$ to $125^{\circ} \mathrm{C}$ [13]. In addition, sensor can operate in normal or "parasite" power supplying mode. It means, that the DS18B20 can derive power directly from the data line ("parasite power"), eliminating the need for an external power supply. The basic parameters are shown in Table 2.

Table 2

Parameters of the DS18B20

\begin{tabular}{lr}
\hline Operating Temperature Range & $-55-125^{\circ} \mathrm{C}$ \\
Supply Voltage & $3-5.5 \mathrm{~V}$ \\
Accuracy & $\pm 0.5^{\circ} \mathrm{C}$ \\
Programmable Resolution & $9-12$ bits \\
Communication interface & $1-$ Wire \\
Pin-Package & TO -92 \\
\hline
\end{tabular}

The last one in comparing is sensor AM2320. This sensor contains beside thermometer also hygrometer. It communicates via $12 \mathrm{C}$ interface. Temperature measurement range is from $-40^{\circ} \mathrm{C}$ to $80^{\circ} \mathrm{C}$. The further similar sensors, which we can find in use, are sensors AM2302, DHT11, DHT12. Those contain except a temperature sensor also a humidity sensor. The difference between these sensors is in measurement range, accuracy and communication interface. The basic parameters are shown in Table 3.

Table 3

Parameters of the AM2320

\begin{tabular}{lr}
\hline Temperature measurement range & $-40-80^{\circ} \mathrm{C}$ \\
Accuracy & $\pm 0.5^{\circ} \mathrm{C}$ \\
Resolution & $0.1^{\circ} \mathrm{C}$ \\
Humidity measurement range & $0-99.9 \%$ \\
Accuracy & $\pm 3 \%$ \\
Resolution & $0.1 \%$ \\
Supply Voltage & $3.1-5.5 \mathrm{~V}$ \\
Communication interface & $12 \mathrm{C}$ \\
\hline
\end{tabular}

The data from thermal sensors are processed with help of Arduino UNO R3. The Microcontroller ATmega 328P represents the basic part of it and it works on $16 \mathrm{MHz}$ frequency. The microcontroller board contain 6 analog pins and 14 digital input/output pins of which 6 can be used as PWM outputs. It contains also power supply pins $+5 \mathrm{~V}$, $+3.3 \mathrm{~V}$ and 3 GND pins. Board is powered through USB or using AC-to-DC adapter 7-16 V.

The connection of sensors can be seen in Fig. 1. Sensor LM35DZ has 3 pins. Pin Vcc is connected to pin $+5 \mathrm{~V}$, GND to ground and Vout to the analog input $A 0$. For sensor DS18B20 was selected "parasite" mode. Pins Vcc and GND of sensor are connected to ground pin of Arduino. Middle pin DQ is connected to digital pin D4 and resistor $4 k 7$ is connected on one end to pin DQ of sensor and on other end to pin $+5 \mathrm{~V}$ of Arduino. Sensor AM2320 has 4 pins. Pin Vcc is connected to pin $+5 \mathrm{~V}$ and pin GND is connected to ground of Arduino. Pins SDA and SCL are connected to analog pins A4 and A5 of Arduino UNO, which are used for I2C communication on this programmable controller board. In wiring there is also included push-button with $10 \mathrm{k} \Omega$ resistor. Button is connected to digital pin D5.

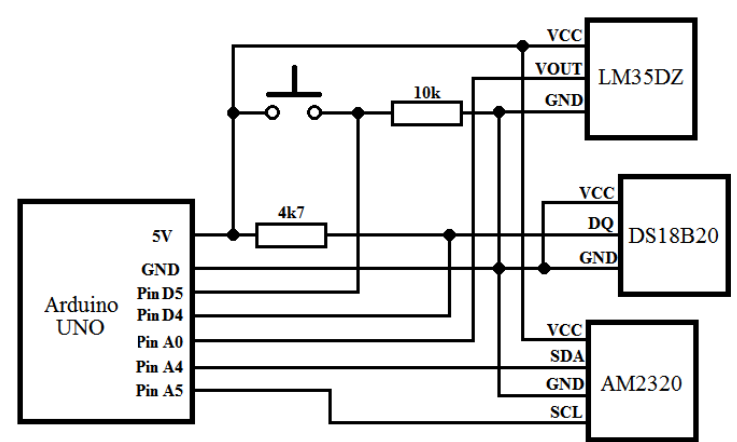

Fig. 1 Wiring scheme of sensors LM35DZ, DS18B20 and AM2320

The program for data reading from temperature sensors was created in Arduino IDE 1.8.2. The program consists of 2 functions: function setup() and loop(). Function setup() is executed once at program startup. In this function speed of communication and pin setup is performed. After function setup() is completed, the function loop() is executed in infinite loop. This function waits until push-button is pressed. When push-button is pressed, ten values 
are read from temperature sensors. For efficient implementation of program there were used freely available libraries for sensors DS18B20 and AM2320.

In Fig. 2 there is block scheme of measuring workplace, where we have tested accuracy of temperature sensors. In experiment was used model of drying-plant at the department of institute. The model consists of a metal construction that represents a model of a hot-air drying-plant where temperature control is taking place. The spiral and cooling fan are used as operational components. The control system is realized with help of programmable logic controller (PLC) OMRON CP1L with touch panel [14]. Measurement was carried out by adjusting the temperature from $25^{\circ} \mathrm{C}$ to $75^{\circ} \mathrm{C}$ stepwise, by step $5^{\circ} \mathrm{C}$. At each step 10 measurements were made. The upper limit has been selected to prevent damage of the AM2320 sensor.

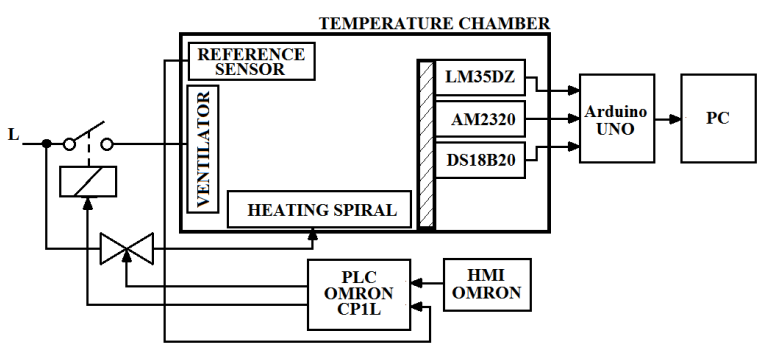

Fig. 2 Block scheme of the measurement workplace

\section{RESULTS OF RESEARCH}

The measured data were processed by Microsoft Excel 2013. We analyzed the measured data and using the analysis of variance we determined the basic statistical characteristic. Then a regression analysis was performed. The results are shown in charts in Fig. 3-5.

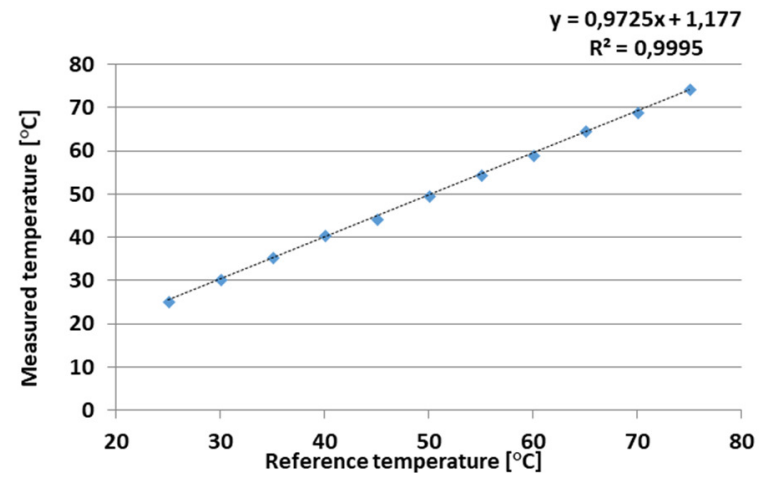

Fig. 3 Course of the measured temperatures from the LM35DZ sensor

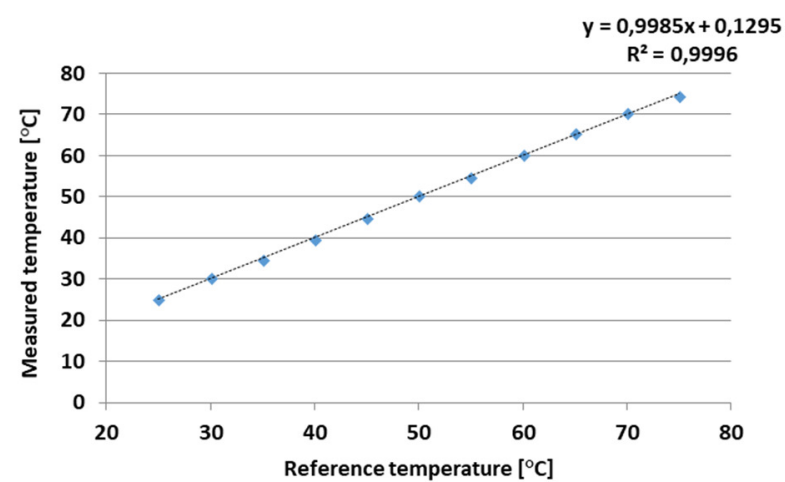

Fig. 4 Course of the measured temperatures from the DS18B20 sensor

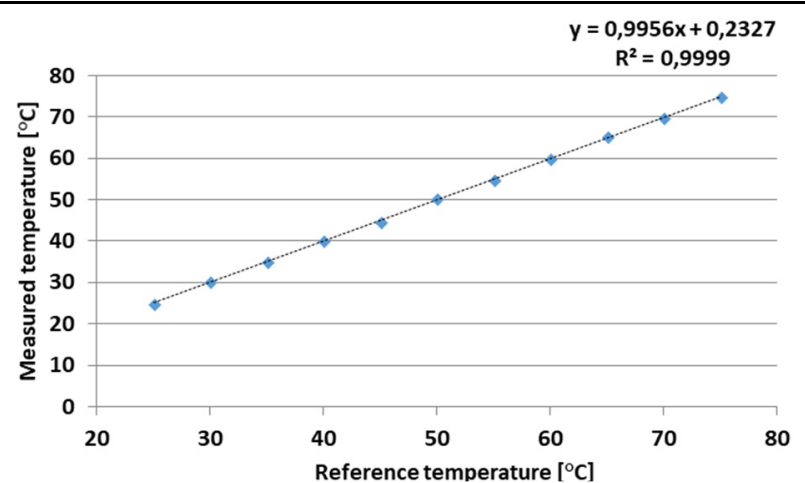

Fig. 5 Course of the measured temperatures from the AM2320 sensor

\section{DISCUSSION}

The analyse of variance has shown, that sensors underrated the measured data. Sensor LM35DZ was the least accurate. Using regression analysis for all sensors were ascertained regression equations of linear regression models were ascertained relation between the real and measured temperature, which we obtained by sensors. We determined the following parameters of regression equation for sensor LM35DZ: $a=0.9725$ and $b=1.177$. In case of sensor DS18B20 are parameters of regression equation: a $=0.9985$ and $b=0.1295$. In case of sensor AM2320 the parameters of regression equation were: $a=0.9956$ and $b$ $=0.2327$. The mathematical model of the sensors DS18B20 and AM2320 is closer to reality than in case of sensor LM35DZ. The gradient of regression function of sensors DS18B20 and AM2320 is closer to the value 1 and $y$-intercept constant is nearer to 0 , than with sensor LM35DZ.

It is obvious from variance and regression analysis of the measured data that sensors DS18B20 and AM2320 measure more accurate than sensor LM35DZ. For more precise measurement the regular calibrating is necessary and also using of further methods and approaches for increasing of measurement accuracy.

Advantages of LM35DZ sensor are output voltage linearlyproportional to the temperature and simple wiring. The accuracy and speed of processing depends on the temperature calculation formula in ${ }^{\circ} \mathrm{C}$ from the value we have got from A/D converter. In case of DS18B20 sensor is the measurement accuracy inversely proportional to the time, which the sensor needs for A/D conversion. In comparison to the LM35DZ sensor, the sensor communicates via the 1-Wire bus while supporting the "parasitic" mode. The AM2320 sensor has a disadvantage of small measuring range compared to the previous sensor. The advantage is that it contains, in addition to the thermometer also a hygrometer and we can communicate with the $12 \mathrm{C}$ bus. All examined sensors have their pros and cons. It is up to the user, which of these sensors is the most suitable for his application.

\section{CONCLUSION}

Temperature measuring and regulation is a dynamic field of industrial automation. The sensors for temperature measuring are produced in many sizes, shapes and precisions to fit requirements of specific tasks. Temperature 
sensor must be periodically calibrated to provide accuracy of measured data. The performance of individual parts of technological equipment could be optimised by calibrating with correct values of uncertainty and thereby make his operation more effective [9].

The current trend in temperature sensors lies in wider use of microelectronic technology e.g. in implementation of semiconductor temperature sensors on a single chip with analogue and digital circuits enabling the connection of sensors to signal busses, in the development of new types of heat radiation detectors, in the integration of temperature sensors into intelligent sensors for automatic correction of variations caused by temperature fluctuations [4]. Practical use of temperature measurement and temperature regulation is in manufacturing engineering in the field of maintenance and technical diagnostics. High demands on reliability and early fault diagnosis are placed on modern machining technology. Each CNC machine has a standard operating diagnostics. The typical quantities, which are tracked, are engine winding temperatures and coolant temperature. Measurement of temperature is important for example in the diagnostics of electrical drives [15], contact stress analysis [16], at determination of residual stresses [17], in vibration signals of machinery [18].

\section{ACKNOWLEDGEMENTS}

This paper was prepared within the work on a research project KEGA 003TU Z-4/2016 "Research and education laboratory for robotics", KEGA 001TU Z-4/2016 "Support of Teaching for Heat and Mass Transfer in Technical Education" and VEGA 1/0086/18 "Researching Temperature Fields in a Set of Shaped Heat Transfer Surfaces".

\section{REFERENCES}

[1] M. Kreidl. Měření teploty - Senzory a měřící obvody. Praha: BEN - technická literatura, 2005.

[2] P. Beneš, J. Chlebný, J. Král, J. Langer and M. Martinásková. Automatizace a automatizační technika 3 - Prostředky automatizační techniky. Brno: Computer Press, 2014.

[3] L. Chybowski, K. Gawdzińska and B. Wiśnicki. “Qualitative importance measures of systems components - a new approach and its applications". Management Systems in Production Engineering, vol. 24, no. 4, pp. 237-246, 2016.

[4] J. Šturcel. Snímače a prevodníky. Bratislava: Vydavatel'stvo STU, 2002.

[5] P. Koleda, P. Koleda and S. Grúbel. "Analysis of temperatures in the mould area during the process of engine cylinder heads casting". Acta facultatis technicae, vol. 1, pp. 31-40, 2016.

[6] S. Gierej. "Big data in the industry - overview of selected issues". Management Systems in Production Engineering, vol. 25, no. 4, pp. 251-254, 2017.

[7] M. Kreidl and R. Šmíd. Technická diagnostika - Senzory, metody, analýza signálu. Praha: BEN - technická literatura, 2006.

[8] P. Beneš, J. Janeček, J. Král, G. Künzel, B. Lacko, J. Semerád, P. Souček, L. Šmejkal, R. Voráček, L. Maixner and B. Šulc. Automatizace a automatizační technika
1 - Systémové pojetí automatizace. Brno: Computer Press, 2012.

[9] R. Strnad. "Měření teploty - porozumění vlastnostem měřicího prístroje". Automa, vol. 15 , no. 6, pp. 31-38, 2009.

[10] S. Surya and S.S. Chauhan. "Water Level Indicator with Temperature Sensor". IOSR Journal of Electrical and Electronics Engineering, vol. 10, no. 3, pp. 65-71, 2015.

[11] P.D. Patil and R.D. Patil. “Designing Multisensor Embedded System Using PSoC". International Journal of Current Advanced Research, vol. 8, no. 4, pp. 271274, 2015.

[12] G. Gricius, D. Drungilas, A. Andziulis, D. Dzemydiene, M. Voznak, M. Kurmis and S. Jakovlev. "Advanced Approach of Multiagent Based Buoy Communication". The Scientific World Journal, vol. 2015, 2015.

[13] H. Jing. "Design and Development of the Temperature Detection System". International Journal of Control and Automation, vol. 8, no. 2, pp. 409-416, 2015.

[14] L'. Naščák and P. Koleda. "Regulácia teploty modelu teplovzdušnej sušiarne programovatel'ným automatom". Acta facultatis technicae, vol. 1, pp. 127-133, 2014.

[15] I.V. Abramov, A.I. Abramov, Z.R. Nikitin, E. Sosnovich, P. Božek and V. Stollmann. "Diagnostics of Electrical Drives", in Proc. of International Conference on Electrical Drives and Power Electronics, 2015, pp. 364-367.

[16] P. Frankovský, O. Ostertag, F. Trebuňa, E. Ostertagová and M. Kelemen. "Methodology of contact stress analysis of gearwheel by means of experimental photoelasticity". Applied optics, vol. 55, no. 18, pp. 4856-4864, 2016.

[17] K. Masláková, F. Trebuňa, P. Frankovský and M. Binda. "Applications of the strain gauge - for determination of residual stresses using ring-core method". Procedia Engineering, vol. 48, pp. 396-401, 2012.

[18] T. Stejskal, J. Kovac and S. Valencik. "Mechanism of randomness in vibration signals of machinery", in Proc. of International Conference on Industrial, Service and Humanoid Robotics, 2012, pp. 257-262.

\section{Ing. Emil Škultéty}

Assoc. Prof. Elena Pivarčiová, PhD.

Ing. Ladislav Karrach

Technical University in Zvolen

Faculty of Environmental and Manufacturing Technology Department of Manufacturing and Automation Technology Študentská 26, 96053 Zvolen, Slovakia

e-mail: xskultetye@tuzvo.sk pivarciova@tuzvo.sk (corresponding author) karrach@zoznam.sk 